\title{
VISUAL SIMULATION METHOD OF RUNOFF IN LANDSCAPE SPACE BASED ON UAV TILT PHOTOGRAPHY
}

\author{
JUNJIE LUO, ZEXIN LEI \& LEI CAO \\ Department of Landscape Architecture, Tianjin University, China
}

\begin{abstract}
Stormwater management caused by site runoff changes has become the focus of current landscape spatial planning. High precision terrain data is conducive to accurate simulation and scientific analysis of runoff. With the popularity of UAV, UAV has been widely used in landscape space planning. This study takes Fangmazhou Park in Hunan Province of China as an example and uses UAV tilt photography to make centimeter-level high-precision 3D models. Based on the Rhino-Grasshopper platform, the real-time rainfall data and the 3D model of the site are parameterized in order to obtain the real-time runoff simulation data and realize the simulation and analysis of the rainwater flow direction, flow rate and inundation range in landscape space. As the basis of landscape space rainstorm waterlogging risk management, this method provides more accurate and effective analysis for landscape spatial planning and performance evaluation.
\end{abstract}

Keywords: UAV, tilt photography, $3 D$ live modeling, parameterization, visualization.

\section{INTRODUCTION}

With the gradual popularization of consumer grade unmanned aerial vehicle (UAV), UAV has been widely used in urban observation [1], power grid inspection [2], agricultural monitoring [3], and other fields. Although UAV related technology has been gradually applied in the design and practice of landscape architecture, most of the application research only stays at the basic aerial photography level, and less applied to the aerial survey with greater potential [4]. Compared with aerial photography, UAV aerial survey is more complex, including the acquisition of spatial data such as digital elevation model (DEM), digital orthophoto model (DOM), digital surface model (DSM) [5]-[7], multi type sensor measurement to obtain plant growth status [8], tilt photogrammetry to obtain 3D scene model, etc. Among them, oblique photography modeling as the current research hotspot of aerial survey [9], research in the field of landscape architecture includes landscape spatial analysis [10], landscape visual experience [11], landscape spatial mapping [12] and so on.

At present, the visualization research of landscape spatial runoff generation and concentration simulation using UAV oblique photography 3D modeling is still in its infancy. Liu Bin et al. carried out large-scale rainfall and flood risk assessment with the submerged depth as the key index through 3D modeling of oblique photography and spatial analysis function of GIS [13]; Wang Wei et al., taking Ziyunyunchuang special town in Nanjing, China as an example, collected the digital terrain of the study area with UAV and carried out hydrological analysis of inundated area with GIS. The relevant research can get the catchment area of the study area, and can be used as the basis for flood prevention landscape design [14]. However, the urban surface hydrological analysis methods based on GIS are mostly suitable for urban scale rainwater collection simulation and calculation, and are not suitable for high precision building scale [15] and small-scale landscape space. In this context, the Rhino-Grasshopper parametric platform with strong expansibility can not only simulate the wind environment and light environment of buildings and landscape space [16], but also carry out visual simulation and analysis of runoff in landscape space by loading 
high-precision 3D real scene model of UAV tilt photogrammetry. The platform can not only break through the limitation of spatial scale, but also simulate the runoff generation situation more vividly, integrate the landscape spatial runoff simulation process more intuitively, and realize the visualization and quantitative analysis of simulation results.

This study takes the visual simulation of rainwater runoff as the breakthrough point, and takes the landscape space of small and medium-sized as the research scope. Taking Fangmazhou Park in Hunan Province of China as a case study, this paper introduces the steps of 3D modeling with geographic information based on UAV tilt photogrammetry technology, and introduces the runoff visualization simulation analysis method of real scene model by using Rhino-Grasshopper parametric platform. This research method can be used as the basis of risk management of rainstorm waterlogging in landscape space, and the simulation results can be used for the optimization design of landscape space, and provide new ideas for the optimization of landscape space layout.

\section{RESEARCH AREA AND RESEARCH METHOD}

\subsection{Research area}

The study area is located in the old city group $\left(111^{\circ} 6^{\prime} 27^{\prime \prime} \mathrm{E}, \quad 29^{\circ} 25^{\prime} 24^{\prime \prime} \mathrm{N}\right)$ south of Cili County, Zhangjiajie City, Hunan Province, China. It is an important tourist city in the middle and lower reaches of the Yangtze River. With the development of urbanization, the flood disaster in Zhangjiajie is becoming more and more serious. The rainstorm in Zhangjiajie mainly occurs from June to August. Due to the short duration and high intensity of rainstorm, it is easy to cause ponding or runoff in some parts of the city to submerge the low-lying areas and form flood disasters.

The study area is located in Section B of Lishui scenic belt and the intersection of Lishui and loushui, which is an important urban waterfront leisure landscape space. The belt Waterfront Park formed in this section is about $500 \mathrm{~m}$ long with a total area of about 5.8 ha. Fitness square, children's paradise, hydrophilic platform and other leisure activities are designed in the park to show the city's brand image, highlight the cultural connotation and enrich the leisure and cultural life of citizens (Fig. 1). Because the study area is located at the confluence of rivers, the view is wide, the spatial scale is pleasant, the tourists are concentrated and the use frequency is high, but it is faced with certain rain flood threat and site rainwater management difficulty. There are many similar urban landscape spaces at home and abroad, so this study has a certain universality.

\subsection{The method of making oblique photographic model and visual simulation of runoff}

\subsubsection{D modeling of UAV oblique photography}

Tilt photography $3 \mathrm{D}$ modeling is an aerial survey method to solve the $3 \mathrm{D}$ real scene model of the object and environment through multiple (usually thousands) continuous photos [17], which is a new data acquisition technology based on visual measurement in recent years. It can not only reflect the texture information of the object and the environment, but also generate the high-precision 3D model with spatial geographic information. Due to the advantages of flexibility, reliability, high precision and low cost, this technology has been widely used in land survey, construction survey, planning and design. 


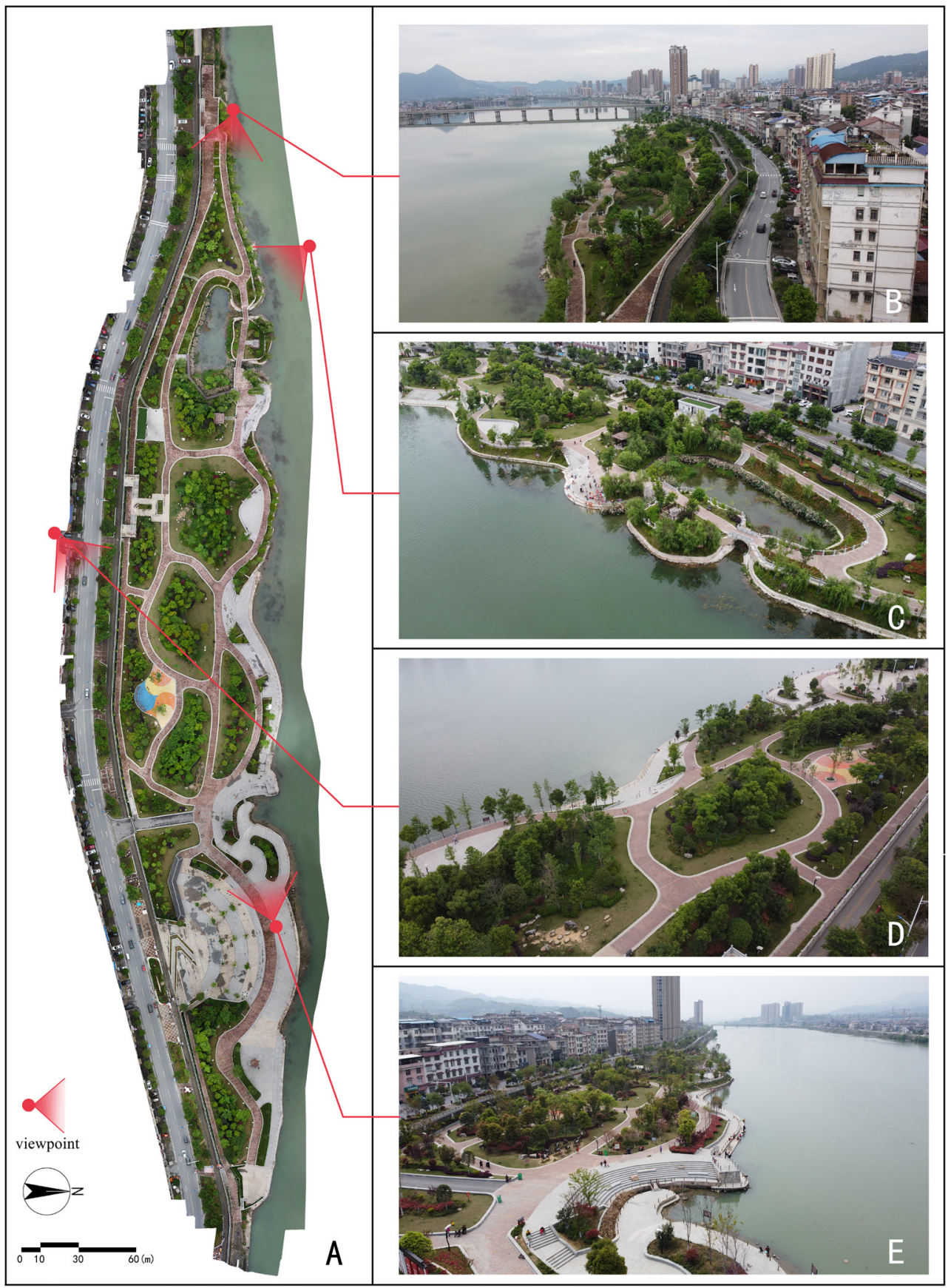

Figure 1: Aerial image of the research area (A is an aerial orthophoto image, B, C, D, and E are aerial images). 

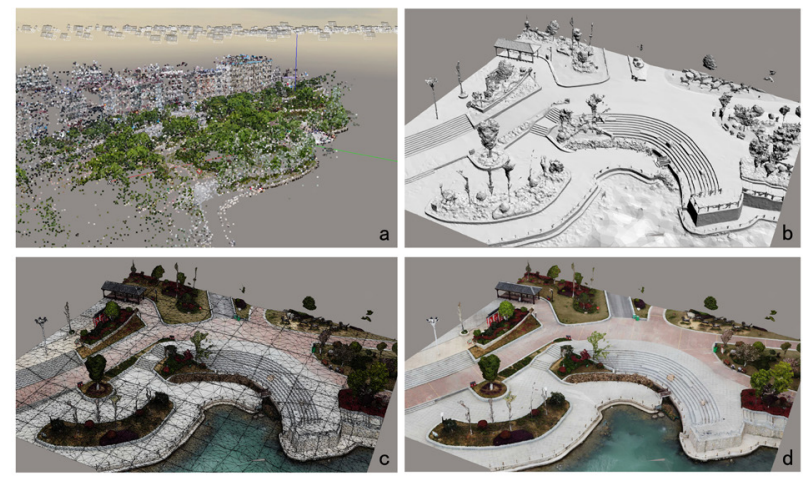

Figure 2: 3D modeling results (part). (a) Point cloud data; (b) Tin white model; (c) Tin mesh model; and (d) 3D real scene model.

The Mavic series and Phantom series UAVs developed by DJI Innovation Technology Co., Ltd. provide excellent flight platforms for obtaining geospatial information. In this study, DJI Mavic 2 professional UAV is selected as the data acquisition platform. Its single endurance time is about 30 minutes, and it is equipped with Hasselblad 1 inch CMOS, viewing angle of $77^{\circ}$, equivalent focal length of $28 \mathrm{~mm}$, and effective pixel of 20 million. Because the research area is located in the open river bank, often accompanied by fast wind speed, the ability of this series of UAVs to effectively resist the wind speed of level 6 provides an effective guarantee for aerial survey. UAV can obtain DOM, DEM and DSM data of the research site by aerial mapping, and $3 \mathrm{D}$ real scene model can be constructed by oblique photography. The specific method and operation process are as follows:

1. Space aerial surveying. Select cloudy days or sun altitude angles greater than $30^{\circ}$ for spatial aerial surveying to reduce the impact of shadows on the aerial model. On the premise that the airworthiness standards are met and flight safety is guaranteed, such as wind speed less than 6 levels, sufficient lighting, low radio interference, etc., the flight altitude is set to $40 \mathrm{~m}$ to obtain richer site information at the lowest possible flight altitude. A total of 58 airborne zones are set up in the aerial survey, with an overlap rate of $80 \%$. Because Mavic 2 Pro is equipped with a single-lens camera, the tilt angle of the cloud platform is adjusted to $30^{\circ}$ and $90^{\circ}$ during aerial surveying, and cross-overlay flight mode is used for image data acquisition to ensure no data omission during the acquisition process, which reduces the impact of consumer-grade UAV single-lens and shorter flight duration. Through 5 batches, a total of 135 minutes and a $17.2 \mathrm{~km}$ air survey, 1624 aerial image data with POS data covering 5.8 ha were obtained.

2. Aerial triangulation. Import aerial imagery with POS data into the Context Capture Center Master (Smart3D) software. Elevation data and plane position of encrypted points are obtained by controlling point encryption and professional data operations on aerial imagery. In this process, only some control points need to be set artificially, and the software will automatically complete the aerial triangulation.

3. 3D modeling. After obtaining the aerial triangulation results from the professional data operation of Context Capture Center Master software, the site model is divided into 10 tiles to generate high-density 3D point clouds. The mesh surface is constructed by 3D point cloud, and the texture information is automatically mapped by the image. Finally, the results of $3 \mathrm{D}$ realistic model with clear texture are generated (Fig. 2). 
4. Model export. The Context Capture Center Master software supports exporting OBJ wavefront format, Collada DAE, ESRI i3s scene database and other data formats. This study chooses OBJ wavefront format data format type to match Rhino-Grasshopper parameterization platform for data processing.

\subsubsection{Visual simulation method of runoff}

Due to the acceleration of urbanization process in recent years, the flood problem caused by the continuous improvement of urban ground hardness ratio has become increasingly prominent, which has become the research focus of landscape planning and design at home and abroad. Scientific visual simulation and analysis of elevation, slope and runoff of urban public space or landscape space can provide accurate and effective data support for rain flood assessment and optimization. Fluid path simulation algorithms based on runoff path simulation can be divided into particle system method and physical model method. Physical model methods are often used for complex fluid calculations because of their large computation and workload. In contrast, the particle system algorithm defines the volume of the object through the particle primitives, which is less computational and therefore more suitable for wind environment simulation and storm runoff simulation of urban landscape.

In this study, we use the Rhino-Grasshopper platform to establish a landscape spatial runoff simulation model based on particle system method. We simulate and analyze the three-dimensional real scene model built by UAV tilt photography (Fig. 3).

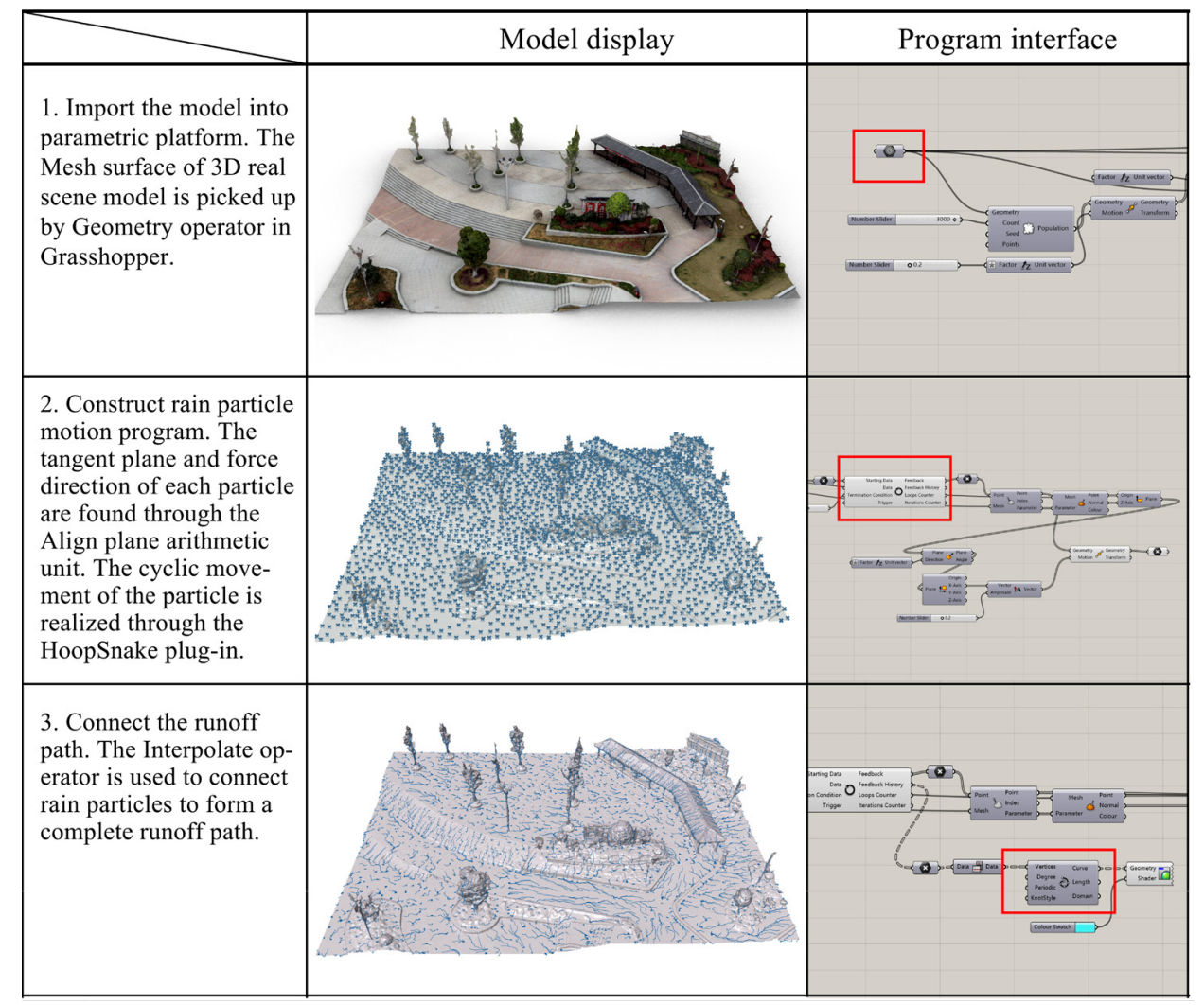

Figure 3: Process and method of visual simulation analysis of runoff. 
Its internal logic can be described as follows: simulating the distribution of rainwater features by setting randomly distributed particles on the mesh surface of a three-dimensional real-world model; simulating the flow of rainwater on the surface by the motion path formed by the force state of particles. The particles released on the mesh surface are affected by gravity and surface supporting force. The trajectories change with the direction of resultant force and move to the lowest point of the surface. The continuous trajectory of all particles on the mesh surface is the runoff path of rainwater. The key to realizing simulation with parameterized platform is the accurate acquisition of the real-world model and its effective connection with the simulation program, which is generally divided into the following steps:

1. Import the model into the parameterized platform. First, the mesh model of UAV tilt photography is imported into Rhino in OBJ format, and the mesh surface of the model is picked up by Geometry in Grasshopper.

2. Construct the rainwater particle movement program. Rainwater simulated particles are constructed using operators such as Populate Geometry and Project Point, and the Align plane operator is used to find the facet on which each particle is located. Rotate the section along the Z-axis to find the steepest aspect of the section. The direction of the steepest downhill on the section is the direction of the force on the particle. The HoopSnake plug-in is used to perform the cyclic movement of the particle on the steepest slope of the cut surface.

3. Connect runoff paths. The Interpolate operator is used to connect rainwater particles from the HoopSnake cycle plug-in operation to form a complete runoff path. A color display is used to set the runoff path to blue for subsequent analysis of the overall situation.

\section{VISUAL SIMULATION OF RUNOFF IN LANDSCAPE SPACE}

\subsection{Visual display of terrain}

Terrain analysis is the basis of landscape spatial runoff research. The parameterized platform based on Rhino-Grasshopper can visualize and display the results of 3D modeling of oblique photography. According to the terrain elevation data, the overall terrain is determined, and the height difference between the highest and lowest points of the site is visually understood by displaying different elevation colors. The visual display and analysis logic is as follows:

1. Pick up the Mesh model obtained by UAV tilt photography, read the elevation point data on the model, and obtain the coordinates of all elevation points;

2. the elevation values are displayed in order from small to large, showing different elevation values from colder to warmer gradation ribbons.

3. mapping the gradient color band representing different elevation values to the site Mesh model, so as to match the model color and the numerical value.

The terrain of the study site shows the feature that the closer to the river surface, the lower the height (Fig. 4). Based on Grasshopper's logical construction process, the terrain model of the park is imported into the logical process, and the elevation analysis map is generated, and the visual model of the site terrain is established. 


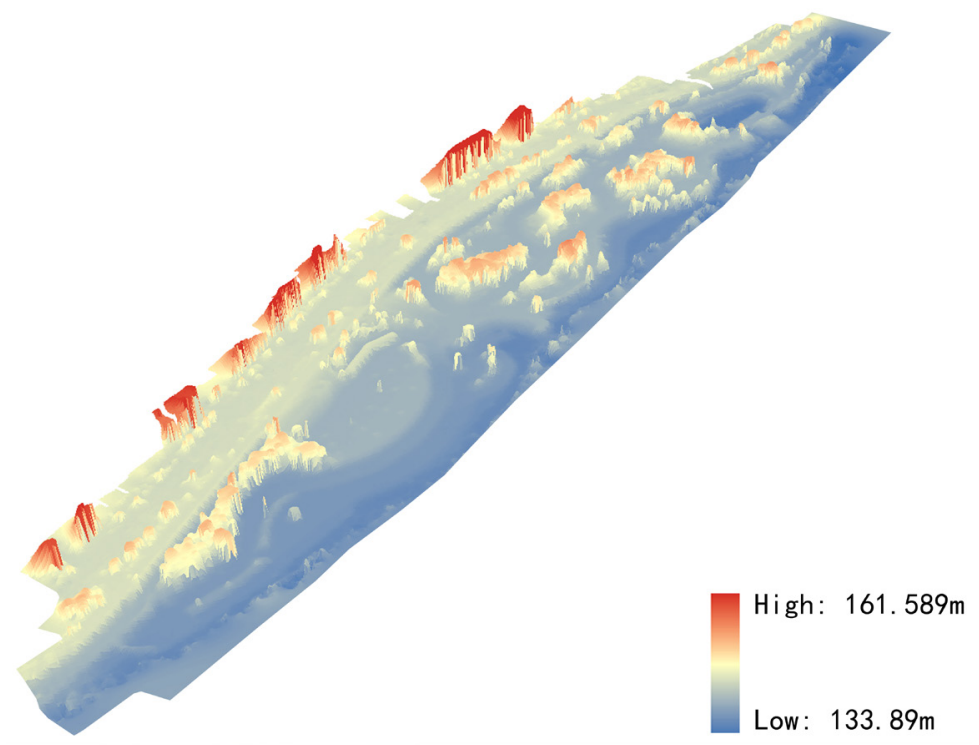

Figure 4: Visual display of terrain.

\subsection{Visual display of rainfall}

Rainfall is the main source of waterlogging disasters, and rainfall is the main driving variable in risk assessment. Obtaining effective meteorological data, analyzing them and visualizing them are very important for preventing and controlling waterlogging disasters. Conduit plug-in based on Rhino-Grasshopper parameterized platform enables custom data visualization and head up display, as well as real-time association with data acquisition.

This study collects real-time precipitation data from local meteorological websites in Zhangjiajie city, uses Conduit plug-in to associate real-time meteorological data with the model on Rhino-Grasshopper parameterized platform, and displays information such as precipitation every six hours and average monthly precipitation throughout the year in the Rhino display interface as a column chart.

According to Fig. 5, the monthly average precipitation in the study area is normal distribution. The highest monthly rainfall is June, with a value of $230 \mathrm{~mm}$. The minimum month is January, with a value of $30 \mathrm{~mm}$. The precipitation in every six hours shows the single day precipitation in the study area on May 29, 2020, and is simulated in real time through the Rhino-Grasshopper parameterization platform. Compared with the traditional precipitation model, a direct linkage relationship between meteorological data obtained from real-time monitoring and site model is established, which provides accurate data for real-time and actual monitoring of stormwater situation.

\subsection{Visual simulation of runoff}

Based on the above 3D visualization model of the park, we can use the Rhino-Grasshopper parameterization platform to load the model and associate with the local real-time rainfall data to achieve the visual simulation of the rainwater path in the landscape space. The key to 


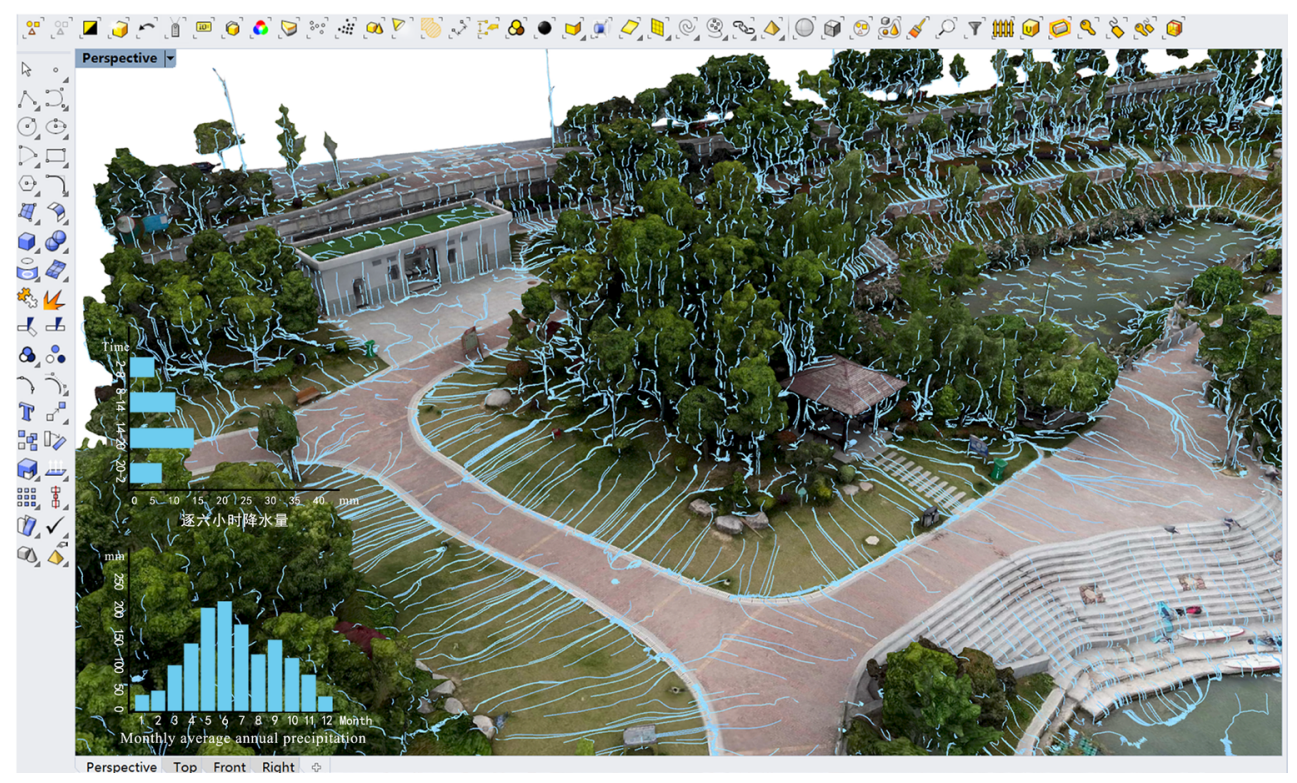

Figure 5: Visual display of rainfall.

the simulation program is to use HoopSnake plug-in to calculate the movement of rainwater particles on the steepest slope of the section. 5000, 10000 and 30000 rain particles were set up on the Mesh terrain surface of the 3D real model respectively, simulating the runoff condition under three different rainfall conditions including light rain, moderate rain and heavy rain. The Amplitude operator in the calculation program can calculate the step length of rain particle movement, which reflects the accuracy of runoff simulation. In this study, the single moving distance of rainwater particles is set to $2 \mathrm{~cm}$ and the number of cycles is 200 times. The aim is to achieve the high accuracy of visual simulation of the path by reducing the single moving distance of rainwater particles. Through the connection with real-time meteorological data, we can realize the automatic simulation display and dynamic analysis of the 3D scene model of the site. The high compatibility of Rhino-Grasshopper parameterized platform can realize the cooperation of multi software platforms including GIS. This research divides the catchment area by the hydrological analysis module of Spatial Analysis tool in GIS, and imports the data of sub-catchment area into Rhino-Grasshopper parameterization platform, which can realize seamless switch of visual simulation of rainwater runoff between single catchment area and the overall site model. Through the visual analysis and simulation of the site runoff under three different rainfall conditions of light rain, moderate rain and heavy rain (Fig. 6), the runoff direction and flow data in different areas of the site can be clearly obtained, and the height of the site can be combined with the elevation analysis, so that the location of the flood point can be further obtained.

\section{RESULTS AND DISCUSSION}

With the rapid development of urbanization in China and the increasing frequency of extreme weather disasters, urban flood problems become more and more serious [18]. Visual simulation and effective analysis of runoff in landscape space mainly consisting of urban 


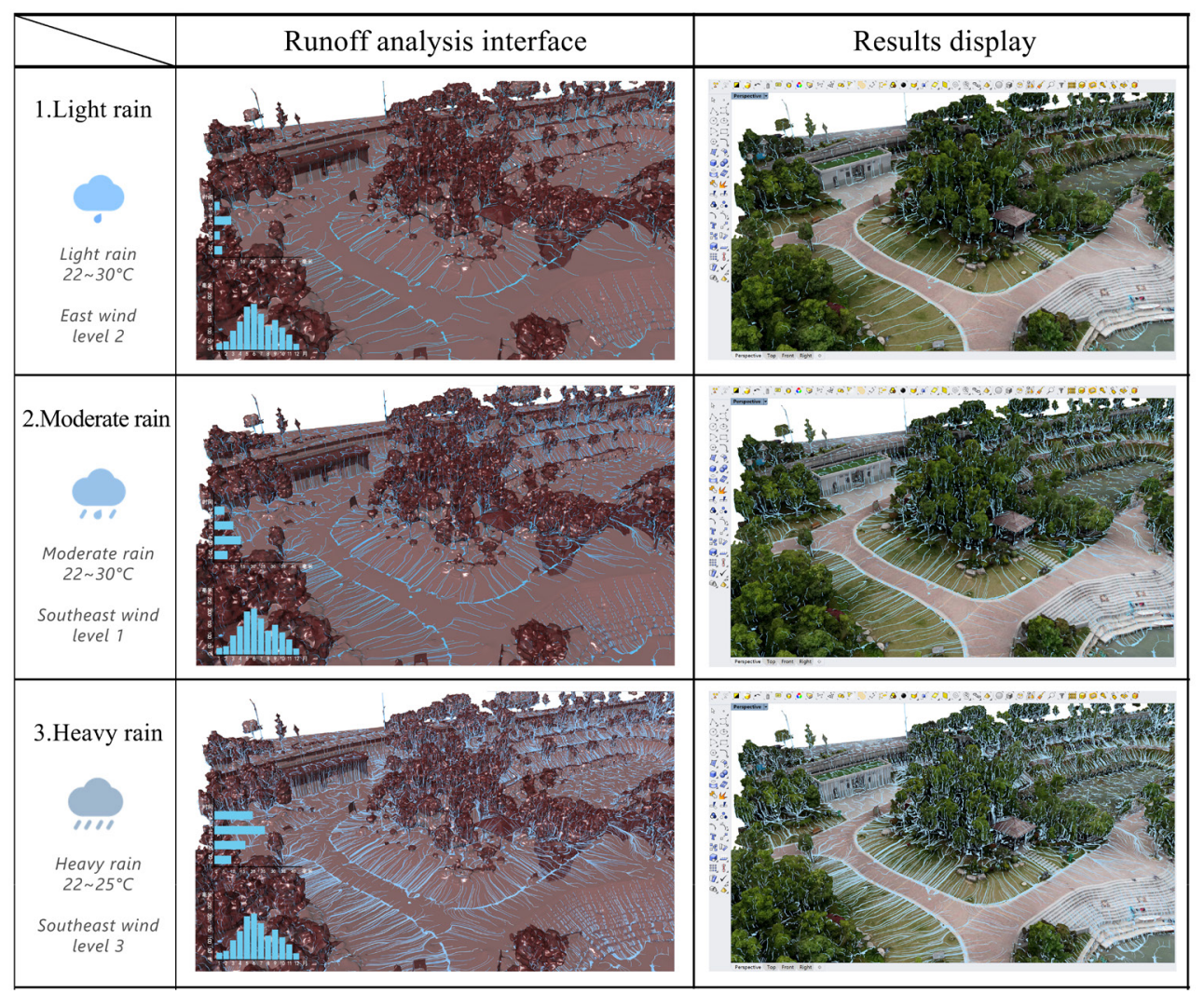

Figure 6: Visual simulation of site runoff under different rainfall conditions.

parks have also become a hot and difficult point in landscape planning and design. UAV tilt photography is a new data acquisition technology which has gradually absorbed the latest achievements in the field of vision measurement [19], It not only can truly reflect the surface morphology, obtain high-precision texture information, but also can generate a real three-dimensional surface model through advanced positioning and modeling technology. In this study, starting from a large number of problems of landscape space runoff which need to be solved urgently in China at present, a centimeter-level high-precision three-dimensional model is made using UAV measurement data, and the motion model of rainwater particles is established by Rhino-Grasshopper parametric platform to realize the visual simulation of landscape space runoff. By linking real-time meteorological data, the 3D model of the scene can be automatically displayed in real time, and the dynamic analysis of flow direction, flow rate and submergence point can be realized. Taking Fangmazhou Park in Zhangjiajie City, Hunan Province as an example, the visual simulation analysis of runoff based on 3D real-world model can intuitively see the runoff in the study area. This method can be used for complex landscape spatial runoff simulation and prediction analysis. As a basis for risk management of rainstorm waterlogging in landscape space, it provides experience for landscape spatial planning and performance evaluation after completion.

As UAV is widely used in landscape architecture planning and design, its high portability and timeliness will help practitioners obtain high-quality digital basic data such as DEM, 
DOM, DSM and 3D real-world model in the research area efficiently and quickly [20], and get rid of the time-consuming and laborious traditional terrestrial surveying or the low resolution of traditional satellite data. The UAV is equipped with a light tilt photogrammetry system which enables fast multi-angle image acquisition at 30-200 m low altitude in the city. One UAV can collect multi-view images of a city within a few days at several square kilometers. As a cutting-edge design tool and technology, parameterization brings about a change in design methods for landscape architecture planning and design, and also gives more scientific significance [21]. Through the combination of UAV aerial survey data and Rhino-Grasshopper parameterization platform, the centimeter-level super resolution data obtained from UAV aerial survey is applied to the study of terrain analysis, line of sight analysis and runoff analysis, providing more accurate data support for related research. UAV tilt photography 3D modeling, as the newly developed aerial survey technology, provides the technology and basic data support for the transformation of traditional gardens to digital gardens and intelligent gardens through the centimeter-level high-precision 3D model generated by them. It also greatly promotes the development and construction of smart city. With the continuous progress of new infrastructure construction such as $5 \mathrm{G}$ network and data center in China [22], and the continuous development of Internet of things and big data analysis, new technologies of digitalization, information and intelligence will surely promote the development of landscape architecture.

\section{REFERENCES}

[1] Park, K. \& Ewing, R., The usability of unmanned aerial vehicles (UAVs) for measuring park-based physical activity. Landscape and Urban Planning, 167, pp. 157-164, 2017.

[2] Zhang, Y., Yuan, X., Li, W. \& Chen, S., Automatic power line inspection using UAV images. Remote Sensing, 9(8), p. 824, 2017.

[3] Gago, J. et al., UAVs challenge to assess water stress for sustainable agriculture. Agricultural Water Management, 153, pp. 9-19, 2015.

[4] Han, W., Wang, Y. \& Guo, W., Application of UAV aerial survey in landscape architecture. Landscape Architecture, pp. 35-40, 2019.

[5] Gašparović, M., Seletković, A., Berta, A. \& Balenović, I., The evaluation of photogrammetry-based DSM from low-cost UAV by LiDAR-based DSM. South-East European Forestry, 8(2), pp. 117-125, 2017.

[6] Scarelli, F.M., Cantelli, L., Barboza, E.G., Rosa, M.L. \& Gabbianelli, G., Natural and anthropogenic coastal system comparison using DSM from a low cost UAV survey (Capão Novo, RS/Brazil). Journal of Coastal Research, 2, pp. 1232-1236, 2016.

[7] Yang, G. et al., The DOM generation and precise radiometric calibration of a UAVmounted miniature snapshot hyperspectral imager. Remote Sensing, 9(7), p. 642, 2017.

[8] Holman, F.H., Riche, A.B., Michalski, A., Castle, M., Wooster, M.J. \& Hawkesford, M.J., High throughput field phenotyping of wheat plant height and growth rate in field plot trials using UAV based remote sensing. Remote Sensing, 8(12), p. 1031, 2016.

[9] Lingua, A., Noardo, F., Spanò, A., Sanna, S. \& Matrone, F., 3D model generation using oblique images acquired by UAV. The International Archives of the Photogrammetry, Remote Sensing and Spatial Information Sciences, 2017.

[10] Li, J., Cheng, X. \& Guo, Y., Application exploration of real-time 3D model in landscape design: A case study of Jinta Park. Chinese Landscape Architecture, pp. 24$28,2017$. 
[11] Unal, M., Bostanci, E. \& Sertalp, E., Distant augmented reality: Bringing a new dimension to user experience using drones. Digital Applications in Archaeology and Cultural Heritage, 17, pp. 1-12, 2020.

[12] Zhang, Q., Liang, H. \& Li, W., Research of the application of digital survey techniques in private garden. Journal of Nanjing Forestry University (Natural Sciences Edition), pp. 1-6, 2018.

[13] Liu, B., Tang, Y. \& Ma, C., Application of 3D modeling of UAV tilt photography in urban rain flood risk assessment. Bulletin of Surveying and Mapping, pp. 46-50, 2019.

[14] Wang, W., Wang, H. \& Li, W., Analysis on comprehensive utilization of landscape water resources based on UAV digital photogrammetry technology. Journal of Nanjing Forestry University (Natural Sciences Edition), pp. 7-14, 2018.

[15] Li, S., Study on nonlinear building design evaluation and optimization strategy based on rainwater harvesting simulation. Harbin Institute of Technology, 2015.

[16] Han, Y., Research on building form generation method based on the influence of sunshine and wind environment. Harbin Institute of Technology, 2013.

[17] Pan, H. \& Ren, D., Application of Smart3D in Real 3D modeling. Geomatics and Spatial Information Technology, pp. 80-84, 2020.

[18] Wang, L., Liao, Y., Yang, L., Li, H., Ye, B. \& Wang, W., Emergency response to and preparedness for extreme weather events and environmental changes in China. Asia Pacific Journal of Public Health, 28(2), pp. 59-66, 2016.

[19] Chunsen, Z. \& Zhang, Q., Research on volumetric calculation of multi-vision geometry UAV image volume. 2018 Fifth International Workshop on Earth Observation and Remote Sensing Applications (EORSA), pp. 1-4, 2018.

[20] Liu, Y., Xinqi, Z., Gang, A., Yi, Z. \& Yuqiang, Z., Generating a high-precision true digital orthophoto map based on UAV images. ISPRS International Journal of GeoInformation, 7(9), p. 333, 2018.

[21] Yuan, Y. \& Cheng, Y., Process, logic and model: Research on parametric landscape architecture planning and design. Chinese Landscape Architecture, pp. 77-82, 2018.

[22] Jiang, Z., Xuanxuan, W., Xun, G. \& Xiang, Z., What are the "new infrastructure" and related values? Open Journal of Business and Management, 8(4), p. 1483, 2020. 